\title{
The expression and clinical significance of miR-132 in gastric cancer patients
}

\author{
Xiaowen Liu ${ }^{1,2}$, Hongmei $\mathrm{Yu}^{1,2}$, Hong Cai ${ }^{1,2}$ and Yanong Wang ${ }^{1,2^{*}}$
}

\begin{abstract}
Background and objective: miR-132 plays a role in regulating neuronal morphology and cellular excitability. Little is known about the effects of miR-132 in cancer. The aim of this study is to evaluate the expression of miR-132 and its clinical significance in gastric cancer.

Methods: Cancerous tissues and corresponding normal tissues from 79 patients with gastric cancer were examined for the expression of miR-132 using quantitative PCR and the association between miR-132 expression levels and clinicopathological factors and prognosis was analyzed.

Results: In 79 clinical samples of gastric cancer patients, miR-132 expression levels in cancer tissues were significantly higher than those in the corresponding normal tissues $(P=0.001)$. Higher expression levels of miR-132 were associated with more frequent lymph node metastasis $(P=0.033)$, more lymphatic tumor emboli $(P=0.007)$, and more advanced stage $(P=0.016)$. Additionally, expression of miR-132 was an independent prognostic factor for overall survival $(P=0.020)$.

Conclusion: miR-132 could serve as an efficient prognostic factor for gastric cancer patients.

Virtual slides: The virtual slide(s) for this article can be found here: http://www.diagnosticpathology.diagnomx.eu/ vs/8168577241196050
\end{abstract}

Keywords: Gastric cancer, Prognosis, Biological markers

\section{Introduction}

Although the incidence of gastric cancer has been substantially declining for several decades, it is still the fourth most common cancer and the second most frequent cause of cancer death [1,2]. A multiple of genes seem to contribute to the malignant biological behaviour of gastric cancer $[3,4]$. It is very important to identify the prognostic factors in order to maximize the therapeutic effect and to minimize the adverse effects in the treatment of cancer patients.

MicroRNAs are a class of endogenous small noncoding RNAs that function as gene regulators by regulating messenger RNA translation and degradation [5]. MicroRNAs play a crucial role in regulating the normal functions such as proliferation, differentiation, and apoptosis. Moreover, dysregulation of miRNAs contribute to the

\footnotetext{
* Correspondence: wangyn1111@hotmail.com

'Department of Gastric Cancer and Soft Tissue Sarcoma, Fudan University

Shanghai Cancer Center, 270 Dong An Road, Shanghai 200032, People's Republic of China

${ }^{2}$ Department of Oncology, Shanghai Medical College, Fudan University, Shanghai 200032, China
}

\section{() Biomed Central}

carcinogenesis and cancer progression [6,7]. As a member of miRNAs family, miR-132 plays an important role in inflammation, angiogenesis, and neural development [8-10]. Recently, some studies showed that the dysregulation of miR-132 was related to a variety of human tumors, such as non-small cell lung cancer, osteosarcoma, breast cancer, hepatocellular carcinoma, prostate cancer, and pancreatic cancer [11-16]. However, there are no reports about the expression and clinical significance of miR-132 in gastric cancer.

In this study, the miR-132 expression in gastric cancer patients was examined and the association between miR-132 and clinicopathological parameters was analyzed. Additionally, we evaluated the expression of some proteins involved in cell-cycle control (p21, p53), tissue proliferation and differentiation (c-myc). p21 and p53 proteins are the products of tumor-suppressor genes, which are activated by modulating cell proliferation via control of the G1 arrest checkpoint of the cell cycle $[17,18]$. c-myc protein is a type of transcription factor. 


\section{Patients and methods}

Human gastric cancer and corresponding normal tissues were obtained from 79 patients who underwent gastrectomy at the Department of Gastric Cancer and Soft Tissue Sarcomas, Fudan University Shanghai Cancer Center, between January 2007 and December 2009. Partial gastrectomy was performed in 36 patients, and total gastrectomy was performed in the other 43 patients. At least $4 \mathrm{~cm}$ resection margins from gross tumor were guaranteed for all patients. A total of 71 patients received adjuvant chemotherapy. After resection, the specimens were immediately frozen in liquid nitrogen and then stored in $-80^{\circ}$ refrigerator. Inclusion criteria for this study were adenocarcinoma and complete pathological data; Exclusion criteria were neoadjuvant therapy, peritoneal dissemination, and distant metastasis. Data were retrieved from their operative and pathological reports, and followup data were obtained by phone outpatient and clinical database. The written informed consent had been obtained from all the patients, and this study was approved by the Ethical Committee of Shanghai Cancer Center of Fudan University.

\section{RNA extraction and quantitative real-time PCR}

The total RNA from tissue was extracted with TRIzol reagent (Invitrogen, Carlsbad, CA, USA) following the manufacturer's instructions. Quantitative real-time PCR (qRT-PCR) assays were carried out to detect the endogenous expression of miR-132 according to the Applied Biosystems method. Briefly, cDNA was reverse transcribed from total RNA samples using a miRNA-specific stemloop primer from the Taqman MicroRNA Assays and reagents from the TaqMan ${ }^{\bullet}$ MicroRNA Reverse Transcription Kit (ABI, Forest City, CA, USA). Then, PCR products were amplified from cDNA samples using the TaqMan MicroRNA Assays together with the TaqMan ${ }^{\bullet}$ Universal PCR Master Mix and the amount of PCR product were monitored using Applied Biosystems 7900 Sequence Detection System. U6 small nuclear RNA was used as an internal control. The relative amount of miR-132 was calculated by using 2(-Delta DeltaC(T)) method [19].

\section{Immunohistochemical staining}

p21, p53, and c-myc were detected by immunohistochemical method. All primary antibodies and mouse monoclonal antibodies were purchased from Dako (Hamburg. Germany). Immunohistochemical staining was performed by the enhance labeled polymer system (ELPS) method. After overnight incubation at $4^{\circ} \mathrm{C}$ with anti-p21, p53, and c-myc antibody, sections were treated according to standard immunoperoxidase methods using a streptavidin biotin peroxidise complex kit (LSAB + Kit/HRP; Dako). The peroxidise reaction was then developed with diaminobenzidine (Dako). Negative control sections were subjected to the same procedure except that the first antibody was replaced by phosphate buffer saline (PBS) [20].

\section{Immunohistochemical staining scoring}

All the slices were evaluated by two pathologists without knowledge of clinical outcome. The percentage of immunoreactive cells and staining intensities were evaluated in each sample. The percentage of immunoreactive cells was graded on a scale of 0 to 4: no staining is scored as 0 , $1-10 \%$ of cells stained scored as $1,11-50 \%$ as $2,51-80 \%$ as 3 , and $81-100 \%$ as 4 . The staining intensities were graded from 0 to 3: 0 is defined as negative, 1 as weak, 2 as moderated, and 3 as strong, respectively. The raw data were converted to the immunohistochemical score (IHS) by multiplying the quantity and intensity scores. On the final analysis, the cases had a score of less than 1 were considered as negative, and $\geq 1$ was regarded as positive [20].

\section{Statistical analysis}

The patients' features and clinicopathological characteristics were analyzed using the two-tailed Student's $t$-test for continuous variable and $x^{2}$ test for categorical variable. Overall survival curves were calculated by Kaplan-Meier method, and the differences between survival curves were examined with long-rank test. The independent prognostic factors were examined by the multivariate survival analysis using Cox proportional hazards model. The accepted level of significance was $P<0.05$. Statistical analyses and graphics were performed using the SPSS 13.0 statistical package (SPSS, Inc., Chicago, IL).

\section{Results}

\section{Clinicopathological characteristics}

There were 62 males and 17 females (3.6:1) with a mean age of 58 years. There was 7 (8.9\%) early gastric cancers and 72 (91.1\%) advanced gastric cancers. According to histological type, well-differentiated tumors were observed in $3(3.8 \%)$ patients, moderately-differentiated in 11 (13.9\%) patients, and poorly-differentiated tumors in remaining 65 $(82.3 \%)$ patients. Of 79 patients, $25(31.6 \%)$ had tumors located in the upper third, 15 (19.0\%) had tumors in the middle third, 36 (45.6\%) had tumors in the lower third of the stomach, and 3 (3.8\%) had tumors occupied two-thirds or more of stomach. Lymph node metastasis was observed in 57 patients, the metastasis rate was $72.2 \%$. The distribution of pathological stage was as follows: $10(12.6 \%)$ patients belonged to stage I, 24 (30.4\%) II, and 45 (57\%) III.

The expression and correlation of miR-132, p21, p53, and c-myc

miR-132 levels in 79 cancerous $(\mathrm{T})$ and corresponding normal tissues $(\mathrm{N})$ were examined by qRT-PCR. Most tumor tissues $(57 / 79,72 \%)$ showed elevated levels of miR132 compared to the corresponding normal tissues, with a 
median increase of 2.3-fold. miR-132 levels in cancerous tissues (mean $\pm \mathrm{SD}, 0.35 \pm 0.58$ ) were significantly higher than those in the corresponding noncancerous tissues (mean $\pm \mathrm{SD}, 0.15 \pm 0.35, P<0.05$ ). The expressions of p21, p53, and c-myc were examined by immunohistochemical staining. p21 expression was positive in $64.6 \%$ of all gastric cancer tissues. p21 staining was observed in the nucleus of carcinoma cells. p53 expression was positive in $74.7 \%$ of all gastric cancer tissues. p53 staining was observed in the nucleus of carcinoma cells. c-myc expression was positive in $44.3 \%$ of all gastric cancer tissues. c-myc staining was observed in the cytoplasm of carcinoma cells. miR-132 expression was associated with p53 and c-myc. There was no correlation with p21. Additionally, p53expression was associated with c-myc (Table 1).

\section{Clinical significance of miR-132 in gastric cancer}

79 gastric cancer patients were divided into two groups including miR-21 high-expression group $(\mathrm{T} / \mathrm{N}>0.5, \mathrm{n}=33$ ) and low-expression group ( $\mathrm{T} / \mathrm{N}<0.5, \mathrm{n}=46)$ according to the median $\mathrm{T} / \mathrm{N}$ ration of miR-132 expression. The correlation between miR-132 expression and pathological parameters was analyzed. The results showed that patients with high miR-132 expression had more frequent lymph node metastasis $(P=0.033)$, more lymphatic tumor emboli $(P=0.007)$, and more advanced stage $(P=0.016)$. However, there were no significant differences about gender, age, histological type, tumor location, tumor size, nervous invasion, and T stage (Table 2). In the overall survival, the patients with the miR-132 high expression had a significantly poorer prognosis than those with miR-132 low expression $(P=0.000)$ (Figure 1$)$. Univariate analysis of overall survival showed that the relative expression of miR-132, nervous invasion, lymphatic tumor emboli, and pathological stage were prognostic predictors. Multivariate survival analysis, including all significant prognostic factors mentioned in univariate analysis, was performed to determine the independent prognostic factors for gastric cancer. Multivariate analysis showed that the miR-132 expression level and pathological stage were independent prognostic factors (Table 3).

\section{Discussion}

The identification of prognostic factors in gastric cancer was essential for predicting patients' survival and determining optimal therapeutic strategies. The depth of invasion

Table 1 Positive results of correlations among biological markers

\begin{tabular}{|c|c|c|c|}
\hline \multicolumn{2}{|c|}{ Biological markers } & \multirow{2}{*}{$\begin{array}{l}\text { Correlation coefficients }(\mathbf{r}) \\
0.274\end{array}$} & \multirow{2}{*}{$\begin{array}{l}\text { P value } \\
0.015\end{array}$} \\
\hline miR-132 & P53 & & \\
\hline miR-132 & c-myc & 0.228 & 0.044 \\
\hline P53 & c-myc & 0.235 & 0.038 \\
\hline
\end{tabular}

Table 2 miR-132 expression and clinicopathological factors

\begin{tabular}{|c|c|c|c|}
\hline Variables & $\begin{array}{l}\text { High expression } \\
\mathrm{n}=33\end{array}$ & $\begin{array}{l}\text { Low expression } \\
\mathrm{n}=46\end{array}$ & $P$ \\
\hline Gender & & & 0.618 \\
\hline Male & 25 & 37 & \\
\hline Female & 8 & 9 & \\
\hline Age & & & 0.556 \\
\hline$<60$ & 18 & 22 & \\
\hline$\geq 60$ & 15 & 24 & \\
\hline Histological grading & & & 0.412 \\
\hline Poorly-differentiated & 28 & 36 & \\
\hline Moderately-differentiated & 5 & 7 & \\
\hline Well-differentiated & 0 & 3 & \\
\hline Tumor location & & & 0.467 \\
\hline Upper third & 10 & 15 & \\
\hline Middle third & 8 & 7 & \\
\hline Lower third & 15 & 21 & \\
\hline Two-third or more & 0 & 3 & \\
\hline Tumor size $(\mathrm{cm})$ & & & 0.862 \\
\hline$<5$ & 18 & 26 & \\
\hline$\geq 5$ & 15 & 20 & \\
\hline Nervous invasion & & & 0.096 \\
\hline Yes & 22 & 22 & \\
\hline No & 11 & 24 & \\
\hline Lymphatic tumor emboli & & & 0.005 \\
\hline Yes & 26 & 22 & \\
\hline No & 7 & 24 & \\
\hline T stage & & & 0.070 \\
\hline $\mathrm{T} 1, \mathrm{~T} 2$ & 6 & 17 & \\
\hline $\mathrm{T} 3, \mathrm{~T} 4$ & 27 & 29 & \\
\hline Lymph node metastasis & & & 0.033 \\
\hline Yes & 28 & 29 & \\
\hline No & 5 & 17 & \\
\hline Pathological stage & & & 0.016 \\
\hline I & 2 & 8 & \\
\hline$\|$ & 6 & 18 & \\
\hline III & 25 & 20 & \\
\hline
\end{tabular}

and lymph node metastasis were the most important prognostic factors in gastric cancer. As a result of the variability of prognosis within same pathological stage of gastric cancer, there have been a lot of researches for specific biological markers to identify patients with prognosis [21-28]. The biological markers such as microRNA, c-Met, L1CAM, endothelial lipase protein, variable copy number of mitochondrial DNA (mtDNA), TIMP3, hK6, and Ezrin have been studied extensively. As a novel biomarker, the potential of miRNAs in predicting prognosis is increasingly 


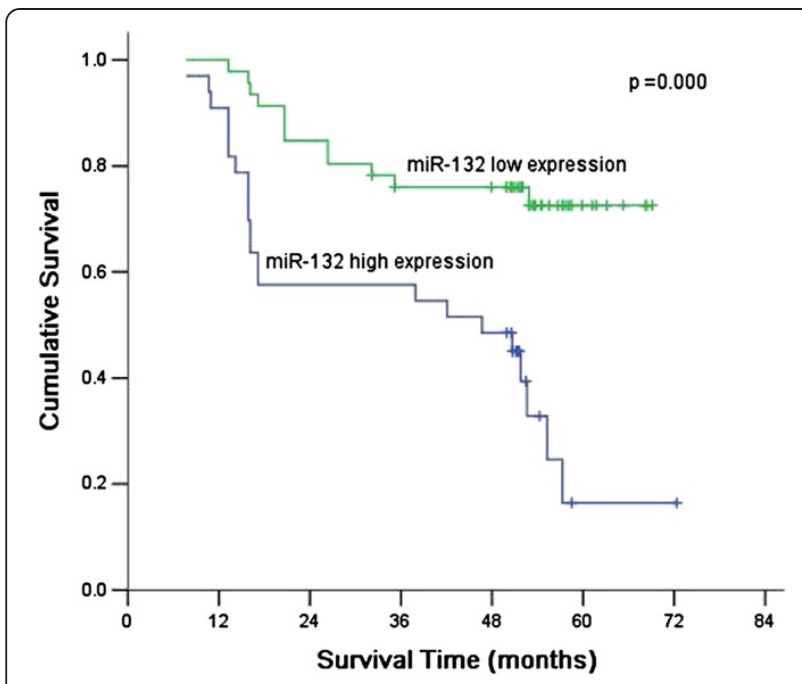

Figure 1 Comparison of survival according to the expression of miR-132. There were significant differences between miR-132 high expression and miR-132 low expression $(P=0.000)$.

studied. miR-132 is a highly conserved miRNA transcribe from an intergenic region on human chromosome 17 by the transcription factor cAMP response element binding protein [29]. Most of the reports bout miR-132 regulation and biological functions emerged from the studies performed in the neuronal context. Additionally, miR-132 has also been described in a number of other fields, such as inflammation, cell transformation and tumourigenesis. miR132 was shown to be up-regulated or down-regulated in different human cancers [16,30,31]. Some studies showed that miR-132 could promote cell proliferation [31]. However, there are still no reports on miR-132 in gastric cancer.

In this study, we investigated miR-132 expression in gastric cancer and determined if it could predict patient outcomes. We found that miR-132 expression was higher in cancerous tissues compared with corresponding normal tissues. The exact cause of the miR-132 high expression in gastric cancer is unknown. Park JK et al. reported [31] that the B2AR agonist terbutaline increases miR-132 expression. miR-132 was transcriptionally activated by CREB in neurons [32]. B2AR antagonists inhibited activation of CREB [33]. Therefore, it is possible that simulation of

Table 3 Multivariate analysis of patients by Cox model

\begin{tabular}{lllll}
\hline Variable & $\mathbf{X}^{\mathbf{2}}$ & $\boldsymbol{P}$ vale & $\mathbf{R R}$ & $\mathbf{9 5 \%} \mathbf{C l}$ \\
\hline miR-132 expression & 5.447 & 0.020 & 2.414 & $1.152-5.059$ \\
Nervous invasion & 1.918 & 0.166 & 1.890 & $0.768-4.655$ \\
Lymphatic tumor emboli & 0.173 & 0.677 & 0.838 & $0.366-1.923$ \\
Pathological stage & 8.742 & 0.003 & 4.356 & $1.642-11.555$ \\
\hline
\end{tabular}

B2AR increase miR-132 expression following activation of CREB.

The results showed that high miR-132 expression in gastric cancer was significantly correlated with aggressive clinicopathological characteristics such as more frequent lymph node metastasis, more lymphatic tumor emboli, and more advanced stage. These results suggested that upregulation of miR-132 played an important role in gastric cancer progression. Interestingly, we found that miR-132 expression was associated with p53 and c-myc. Some previous studies showed that some microRNAs could mediate and regulate tumor suppression exerted by p53 or c-myc [34,35]. Jiang $L$ et al. [34] found that has-miR-125a-3p could induce apoptosis via the p53 pathway. Zhang N, et al. [35] found that miR150 could promote the proliferation of lung cancer cells by targeting p53. Wang B et al. [36] found that there was a double negative feedback loop between miR-122 and c-myc in hepatocellular cancer. Li X, et al. [37] found that c-MYC promoted the expression of mature miR-23a, miR24-2, and miR27a and subsequently promoted mammary carcinoma cell migration and invasion. However, the exact correlation between miR-132 and p53, c-myc is unclear and remains to be elucidated in future studies. We investigated the correlation of miR132 expression with prognosis of gastric cancer patients, found that patients with high miR-132 expression had poorer overall survival that those with low miR-132 expression. More importantly, multivariate analysis revealed that high miR-132 expression was independent prognostic indicator. It was controversy whether miR132 played same prognostic value in different kinds of tumors. Parker et al. reported [38] that high expression of miR-132 was associated with poor prognosis in patients with primary glioblastoma multiforme. However, Yang et al. [12] reported that osteosarcoma patients with low miR-132 expression had poorer overall and diseasefree survival. It was possible that miR-132 played different functions in different tumors. Wang et al. [39] found that overexpression of miR-132 suppressed in vitro cell proliferation and in vivo tumor growth. Li et al. [13] showed that overexpression of miR-132 could inhibit the proliferation of breast cancer cell. Conversely, Park et al. [31] reported that over-expression of miR-132 increased the pancreatic cancer cell proliferation.

Taken together, our study indicated that miR-132 was upregulated in gastric cancer and might be an independent molecular biomarker for predicting the prognosis of gastric cancer. Meanwhile, as a result of small sample research, a large case research is needed to confirm the prognostic value of miR-132 in gastric cancer. 


\section{Authors' contributions}

Conceived and designed the experiments: XWL HMY HC YNW. Performed the experiments: XWL. Analyzed the data: XWL HMY. Contributed reagents/ materials/analysis tools: HC YNW. Wrote the paper: XWL. All authors read and approved the final manuscript

Received: 25 January 2014 Accepted: 3 March 2014

Published: 12 March 2014

\section{References}

1. Shibata A, Parsonnet J: Stomach cancer. In Cancer Epidemiology and Prevention. 3rd edition. Edited by Schottenfeld D, Fraumeni JF. New York: Oxford University Press; 2006:707-720.

2. Parkin DM, Bray F, Ferlay J, Pisani P: Global cancer statistics, 2002 CA Cancer J Clin 2005, 55:74-108.

3. Scartozzi M, Bittoni A, Pistelli M, Galizia E, Berardi R, Giampieri R, Faloppi L, Cascinu S: Toward molecularly selected chemotherapy for advanced gastric cancer: stage of the art and future perspectives. Cancer Treat Rev 2009, 35(5):451-462

4. Panani AD: Cytogenetic and molecular aspects of gastric cancer: clinical implications. Cancer Lett 2008, 266(2):99-115.

5. Hutvágner G, Zamore PD: A microRNA in a multiple-turnover RNAi enzyme complex. Science 2002, 297(5589):2056-2060.

6. Calin GA, Croce CM: MicroRNA signatures in human cancers. Nat Rev Cancer 2006, 6:857-866.

7. Parikh A, Lee C, Peronne J, Marchini S, Baccarini A, Kolev V, Romualdi C, Fruscio R, Shah H, Wang F, Mullokandov G, Fishman D, D'Incalci M, Rahaman J, Kalir T, Redline RW, Brown BD, Narla G, DiFeo A: microRNA-181a has a critical role in ovarian cancer progression through the regulation of the epithelialmesenchymal transition. Nat Commun 2014, 5:2977.

8. Shaked I, Meerson A, Wolf Y, Avni R, Greenberg D, Gilboa-Geffen A, Soreq H: MicroRNA-132 potentiates cholinergic anti-inflammatory signalling by targeting acetylcholinesterase. Immunity 2009, 31(6):965-973.

9. Mulik S, Xu J, Reddy PB, Mulik S, Xu J, Reddy PB, Rajasaqi NK, Gimenez F, Sharma S, Lu PY, Rouse BT: Role of miR-132 in angiogenesis after ocular infection with herpes simplex virus. Am J Pathol 2012, 181(2):525-534.

10. Magill ST, Cambronne XA, Luikart BW, Lioy DT, Leighton BH, Westbrook GL, Mandel G, Goodman RH: microRNA-132 regulates dendritic growth and arborization of newborn neurons in the adult hippocampus. Proc Natl Acad Sci USA 2010, 107(47):20382-20387.

11. Zhang B, Lu L, Zhang X, Ye W, Wu J, Xi Q, Zhang X: Has-miR-132 regulates apoptosis in Non-small cell lung cancer independent of acetylcholinesterase. J Mol Neurosci 2013 [Epub ahead of print].

12. Yang J, Gao T, Tang J, Cai H, Lin L, Fu S: Loss of microRNA-132 predicts poor prognosis in patients with primary osteosarcoma. Mol Cell Biochem 2013, 381(1-2):9-15.

13. Li S, Meng H, Zhou F, Zhai L, Zhang L, Gu F, Fan Y, Lang R, Fu L, Gu L, Qi L. MicroRNA-132 is frequently down-regulated in ductal carcinoma in situ (DCIS) of breast and acts as a tumor suppressor by inhibiting cell proliferation. Pathol Res Pract 2013, 209(3):179-183.

14. Wei X, Tan C, Tang C, Ren G, Xiang T, Qiu Z, Liu R, Wu Z: Epigenetic repression of miR-132 expression by the hepatitis $B$ virus $x$ protein in hepatitis B virus-related hepatocellular carcinoma. Cell Signal 2013, 25(5):1037-1043.

15. Formosa A, Lena AM, Markert EK, Cortelli S, Miano R, Mauriello A, Croce N, Vandesompele J, Mestdagh P, Finazzi-Agrò E, Levine AJ, Melino G, Bernardini S, Candi E: DNA methylation silences miR-132 in prostate cancer. Oncogene 2013, 32(1):127-134.

16. Zhang S, Hao J, Xie F, Hu X, Liu C, Tong J, Zhou J, Wu J, Shao C: Downregulation of miR-132 by promoter methylation contributes to pancreatic cancer development. Carcinogenesis 2011, 32(8):1183-1189.

17. Fenoglio-Preiser CM, Wang J, Stemmermann GN, Noffsinger A: TP53 and gastric carcinoma: a review. Hum Mutat 2003, 21:258-270.

18. Wiksten JP, Lundin J, Nordling S, Kokkola A, von Boguslawski k, Haglund C. The prognostic value of p27 in gastric cancer. Oncology 2002, 63:180-184.

19. Livak KJ, Schmittgen TD: Analysis of relative gene expression data using real-time quantitative PCR and the 2(-Delta DeltaC(T)) method. Methods 2001, 25:402-408.

20. Liu X, Cai H, Huang H, Long Z, Shi Y, Wang Y: The prognostic significance of apoptosis-related biological markers in Chinese gastric cancer patients. PLoS One 2011, 6(12):e29670.
21. Song F, Yang D, Liu B, Guo Y, Zheng H, Li L, Wang T, Yu J, Zhao Y, Niu R, Liang $\mathrm{H}$, Winkler $\mathrm{H}$, Zhang W, Hao X, Chen $\mathrm{K}$ : Integrated microRNA network analyses identify a poor-prognosis subtype of gastric cancer characterized by the miR-200 family. Clin Cancer Res 2014, 20(4):878-889.

22. Yu S, YU Y, Zhao N, Cui J, Li W, Liu T: c-Met as a prognostic marker in gastric cancer: a systematic review and meta-analysis. PLoS One 2013 8(11):e79137.

23. Ito T, Yamada S, Tanaka C, Ito S, Murai T, Kobayashi D, Fujii T, Nakayama G, Sugimoto H, Koike M, Nomoto S, Fujiwara M, Kodera Y: Overexpression of L1CAM is associated with tumor progression and prognosis via ERK signaling in gastric cancer. Ann Surg Oncol 2014, 21(2):560-568.

24. Dong X, Wang G, Zhang G, Ni Z, Suo J, Cui J, Cui A, Yang Q, Xu Y, Li F: The endothelial lipase protein is promising urinary biomarker for diagnosis of gastric cancer. Diagn Pathol 2013, 8:45

25. Zhang G, Qu Y, Dang S, Yang Q, Shi B, Hou P: Variable copy number of mitochondrial DNA (mtDNA) predicts worse prognosis in advanced gastric cancer patients. Diagn Pathol 2013, 8(1):173.

26. Guan Z, Zhang J, Song S, Dai D: Promoter methylation and expression of TIMP3 gene in gastric cancer. Diagn Pathol 2013, 8(1):110.

27. Liu X, Xiong H, Li J, He Y, Yuan X: Correlation of hK6 expression with tumor recurrence and prognosis in advanced gastric cancer. Diagn Pathol 2013, 8:62.

28. Jin J, Jin T, Quan M, Piao Y, Lin Z: Ezrin overexpression predicts the poor prognosis of gastric adenocarcinoma. Diagn Pathol 2012, 7:135.

29. Nudelman AS, DiRocco DP, Lambert TJ, Garelick MG, Le J, Nathanson NM, Storm DR: Neuronal activity rapidly induces transcription of the CREB-regulated microRNA-132, in vivo. Hippocampus 2010, 20(4):492-498.

30. Anand S, Majeti BK, Acevedo LM, Murphy EA, Mukthavaram R, Scheppke L, Huang M, Shields DJ, Lindquist JN, Lapinski PE, King PD, Weis SM, Cheresh DA: MicroRNA-132-mediated loss of p120RasGAP activates the endothelium to facilitate pathological angiogenesis. Nat Med 2010, 16(8):909-914.

31. Park JK, Henry JC, Jiang J, Esau C, Gusev Y, Lerner MR, Postier RG, Brackett DJ, Schmittgen TD: miR-132 and miR212 are increased in pancreatic cancer and target the retinoblastoma tumor suppressor. Biochem Biophys Res Commun 2011, 406(4):518-523.

32. Vo N, Klein ME, Varlamova O, Keller DM, Yamamoto T, Goodman RH, Impey S: A cAMP-response element binding protein-induced microRNA regulates neuronal morphogenesis. Proc Natl Acad Sci USA 2005, 102(45):16426-16431.

33. Zhang D, Ma QY, Hu HT, Zhang M: beta2-adrenergic antagonists suppress pancreatic cancer cell invasion by inhibiting CREB, NFkappaB and AP-1. Cancer Biol Ther 2010, 10:19-29.

34. Jiang L, Chang J, Zhang Q, Sun L, Qiu X: MicroRNA has-miR-125a-3p activates p53 and induces apoptosis in lung cancer cells. Cancer Invest 2013, 31(8):538-544.

35. Zhang $N$, Wei $X, X u L:$ miR-150 promotes the proliferation of lung cancer cells by targeting P53. FEBS Lett 2013, 587(15):2346-2351.

36. Wang B, Hsu SH, Wang X, Kutay H, Bid HK, Yu J, Ganju RK, Jacob ST, Yuneva M, Ghoshal K: Reciprocal regulation of microRNA-122 and c-Myc in hepatocellular cancer: role of E2F1 and transcription factor dimerization partner 2. Hepatology 2014, 59(2):555-566.

37. Li X, Liu X, Xu W, Zhou P, Gao P, Jiang S, Lobie PE, Zhu T: c-MYC-regulated miR-23a/24-2/27a cluster promotes mammary carcinoma cell invasion and hepatic metastasis by targeting sprouty2. J Biol Chem 2013, 288(25):18121-18133.

38. Parker NR, Correia N, Crossley B, Buckland ME, Howell VM, Wheeler HR: Correlation of MicroRNA 132 Up-regulation with an unfavorable clinical outcome in patients with primary glioblastoma multiforme treated with radiotherapy plus concomitant and adjuvant temozolomide chemotherapy. Trans/ Oncol 2013, 6(6):742-748.

39. Wang J, Xu G, Shen F, Kang Y: miR-132 targeting cyclin E1 suppresses cell proliferation in osteosarcoma cells. Tumour Biol 2014 [Epub ahead of print].

doi:10.1186/1746-1596-9-57

Cite this article as: Liu et al:: The expression and clinical significance of miR-132 in gastric cancer patients. Diagnostic Pathology 2014 9:57. 